\title{
Survey the Relation between Social Capital and Organizational Silence (Study about: The Employees of Governmental Organizations in Marivan)
}

\author{
Parviz Kafcheh, Bahia Lotfi (Responsible Author) \\ Department of Management, Islamic Azad University, \\ Sanandaj Branch, Sanandaj, Iran
}

\section{Keywords: Organizational Silence, Social Capital, Governmental Organizations, Marivan City.}

\begin{abstract}
This article aims to survey the relation of social capital of employees and their organizational silence in governmental organizations of Marivan in 1994. The statistics society of the research was consisted of all employees in governmental organizations of Marivan (600), that 377 persons was determined as statistics sample. The method of the research was descriptive with from the correlation style. The information (data) collector tool was two questionnaires of Nahapieta \& Ghoshal (1998) and the Organizational Silence questionnaire of Pinder and Harlos model (2001). The validity of questionnaire was orderly measured $0 / 86$ and $0 / 83$. The gathered data was measured and analysed by using the statistic tests after Regression analysis. The results of Regression analysis illustrate that two dimensions of social capital are purely specifying (explaining) 58 percent of Organizational Silence variance, and the variable of organizational structure of employees is being studied with the most effective and determinative factor on Organizational Silence in society, this factor is reversely explaining the 63 percent of dependent variable changes; and the variable of relational capital of employees is the second effective factor on Organizational Silence in society which is being studied, this factor also explaining 19 percent of dependent variable changes.
\end{abstract}

\section{INTRODUCTION}

Most of the governmental organizations have admitted that the process of innovation in their organizations is normally very slow and in some cases, they have also experienced the failure. This unpleasant result in addition to have correspondence with Bureaucracy's risk-averse and related Organizational Silences, it's also depended on the employees' decision toward the presentation of innovated suggestions (Sydanlo, 22: 2012). The Organizational Silence is in relation with the restriction of organizational decisions effectiveness and process of revolution. The problem which currently beset the most of organizations is that they are suffering from the deficiency (shortage) of their employees comments. When this happens, the quality of decision-making and doing changes will decrease. Also Organizational Silence prevent the effective organizational development and changes by avoiding the negative feedback. Because organization doesn't have ability to survey and correct the faults and errors (Morrison, E. W. and Milliken, F. 707: 2000). One of the variables that can affect the organizational silence is social capital. The concept of social capital is referring to linkage and communication between the members of a network as a valuable resource, and it realizes the member's goals by creating norms and mutual trust (Alvani et al, 36: 2007). The previous researches show that the organizations which have high levels of social capital, they have individuals engage and undertake to the organization, and employees are involves in the organizational activities and give an identity to the formation (organization), and the employees who are witness of powerful communicational norms in organization, they are more faithful to the organization values; with the communication increment between persons, the costs of transactions are gotten lower and this is an competitive advantage for organization (Archie Bong and Aniyancie, 28: 2004). Inertia (slowness in working) of organizations employees in Iran is besetting some governmental organizations and some non-governmental and personal organizations. The employees silence and disappointment to programs and fate of the organization and effective 
perception and agreement between employees and managers are an alarm for the organizational function and performance decrement, and this subject has a double importance in training and teaching (organization) because of its training (base), and this matter generally can hurt or cause damage for society. One of the reasons of inertia is the organizational incuriosity (Danaiefard et al, 81: 2010). Undoubtedly, the importance and effectiveness of persons in service and productive organizations are not hiding (invisible) for anyone. The problem which currently beset the most of organizations is that they are suffering from the deficiency (shortage) of their employees comments. When this happens, the quality of decision-making and doing changes will decrease. Also Organizational Silence prevent the effective organizational development and changes by avoiding the negative feedback. Because organization doesn't have ability to survey and correct the faults and errors, therefore the organizations that want to be innovation and don't exit and egress from the competitive circles of current competitive world, should overcome this silence. The ways of overcoming to this silence are different. Nowadays, the psychologists and researches believe that (the organizations) should notify and pay attention to the positive aspects and behavioural abilities of persons in organizations so that employees can overcome their weaknesses and also easily express their comments and ideas, and organizations can have more creative employees, therefore according to our (research), the social capital in organization can cause a decrement in employees silence. Regarding to this matter, the elimination of the employees silence can has positive effects such as increment in production and efficiency, the good and satisfactory feeling of employees to themselves and workplace, increment in decision-making quality, collaboration and even knowledge sharing and so on in the organizations. So doing such research is necessary and essential. According to the presented information, the main purpose of the research (article) is determining the relation between employees' social capital and their organizational silence.

\section{THEORETICAL BASIS}

\subsection{Social Capital}

Putnam knew the social capital as a device for achieving to the social and political development in different political systems. His main emphasis was on the concept of "trust'" and according to his (opinion), it was the factor that could cause political development by attracting the trust between people and statesmen and political elites (Alvani, 6: 2003). Bordio defined this concept as sum result (collection) of actually and potential resources which is depended on the stable network ownership of relationships that is institutionalized with the communication or cognition (Portsmouth, 308: 2005).

\section{- The Elements and Ingredients of Social Capital}

According to the Nahapiet \& Ghoshal (1988) opinion, the social capital means a collection of actual and potential resources which have existed and available in the relational network that people have and it's also derived from it. Since social capital is a collection of relations, so it's included of different aspects and it can be surveyed in three dimensions, structural, relational and cognitive dimensions (Alvani and Abdollahpour, 12: 2008).

\section{- Structural Dimension of Social Capital}

The definition of Portes emphasizes on structural dimension of social capital. He believes that social capital is the ability of people for possessing the scarce resources due to the membership quality in wider social structures and networks; the definition that Coleman illustrate is emphasizing on the structural dimension. He is expressing that social capital is consisting of a dimension of social capital which makes the people's action easy in the structure. Nahapiet \& Ghoshal define the structural dimension of social capital as relational patterns between the members of a group or social unit that is consisted of network linkage, the elements (ingredients) of network and network stability (Nahapiet \& Ghoshal, 25: 1998). 


\section{- Relational Dimension of Social Capital}

This kind of capital is referring to the more abstract manifestations of social capital such as trust, norms and values which affect the mutual interactions between people. This values are more consisting of trust, solidarity, cooperation, forgiveness and civil culture that is mutual between a society's members and cause a cooperation between the people of a society for reaching the mutual benefits. The relational dimension of social capital is referring to the level of trust and mutual relations between the members of a united society (Lock Lee, 123: 2005). The relational dimension of social capital is about the personal relations that persons make during their interactions. The main notifying focus of the relational dimension of social capital is stable based on the special relations such as: respect, trust, bailment, kindness and intimacy that people show in their interactions with others; for example if two entrepreneurs that have same networks and conditions have different personal relation with the other members of network, then the reactions and results that they get (achieve) will be different (Alvani and Abdullapour, 15: 2008).

\section{- Cognitive Dimension of Social Capital}

The cognitive dimension is consisting of perceptions, beliefs and social and cultural imaginations that and have been accepted and remained between people by mutual concepts and memories or mutual language; this dimension is also consisting of mutual purposes and culture. Mutual purposes are the perception level and mutual attitude of united society's members toward the purposes and results of group activities. For example, the level of members' willing for participating in the group activities in organization shows the level of their culture (Alvani et al, 43: 2007).

\section{- The Importance of Social Capital in Organization and Management}

The organizations that have higher levels of social capital are probably more successful than their competitions with lower level of social capital (Nahapiet and Ghoshal, 250: 1998). On the other hand, there is meaningful and positive relation between the social capitals, employees' commitment, organization flexibility, the appropriate management of plural interactions and creating high levels of conceptual capital. Hence, the social capital can improve the organizational performance (Bolino et al, 507, 2002). The social organizational capital is a property that is useful for the organization through creating the value for stakeholders and also for the organization members by developing the skills of employees (Leana \& Van Buren, 538, 1999).

\subsection{Organizational silence}

Pinder and Harlos define the organizational silence as the restraint of employees from illustrating and expressing the behavioural and cognitive evaluations and effectiveness about the situations and conditions of organization (Pinder and Harlos, 2001). Morrison and Milliken also consider the organizational silence as a social phenomenon that employees are avoiding to present their own ideas and comments about the organization issues. The indexes of organizational silence are defined as follows:

\section{- Altruistic Silence}

The altruistic silence is based on the literature of organizational citizenship behaviour (Avery and Quinones, 2002) and it's avoiding from expressing the ideas, information and comments that related to the work in order to cause advantage for the other persons in organization and based on the motivation of altruism, collaboration and cooperation.

\section{- Defensive Silence}

The motivation of this kind of silence is the fear of person from presenting the information. Actually, sometimes persons may avoid to present the related ideas, information or comments for protecting their own condition (the motivation of self-protection). The defensive silence is an 
intentional and passive behaviour that is used in order to keep oneself from external threats (Avery and Quinones, 2002).

\section{- Submissive Silence}

Whenever that most of the people call and know a person as silent, they actually mean that s/he does not actively communicate (with others). The resulted silence of this behaviour is called submissive silence and it's referring as restraint from presenting ideas, information or related comments based upon the submission and satisfaction from any conditions. So the submissive silence shows a withdrawal behaviour that it usually has passive status instead of being active (Pinder and Harlos, 2001). According to the research, we consider the dimensions and elements of organizational silence comprised of three dimensions and social capital is extracted based on the theoretical background (history) and also according to the research of Nahapiet and Ghoshal and their three components.

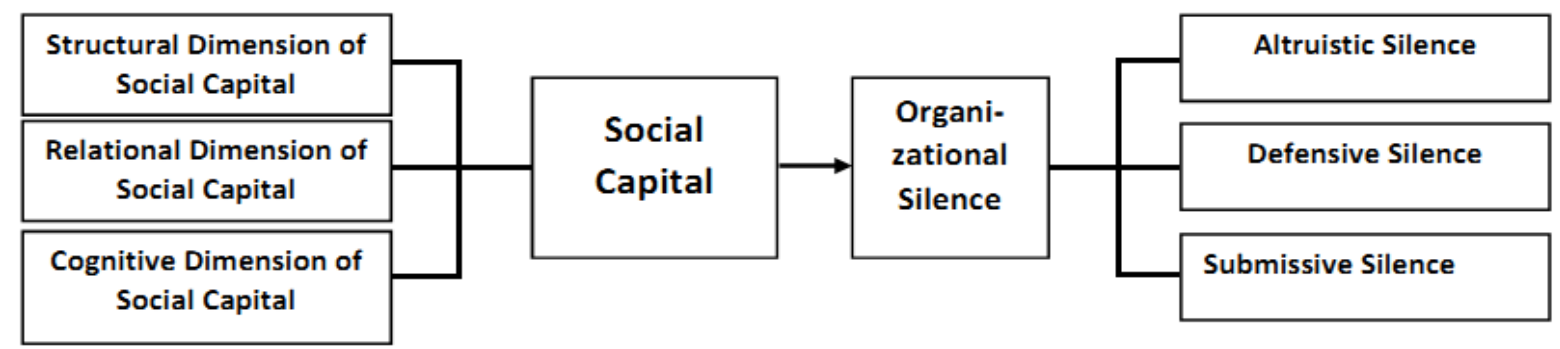

Diagram (2.3.) Model of Research Analysis

Reference of social capital model: Nahapiet and Ghoshal (1988)

Reference of organizational silence: Pinder and Harlos (2001)

\section{ACCORDING TO THE MENTIONED INFORMATION, HYPOTHESISES ARE AS FOLLOWS:}

\subsection{Main Hypothesis:}

There is meaningful relation between social capital and organizational silence of employees in governmental organizations in Marivan.

\subsection{Secondary Hypothesises:}

- There is meaningful relation between relational dimension of social capital and organizational silence of employees in governmental organizations in Marivan.

- There is meaningful relation between cognitive dimension of social capital and organizational silence of employees in governmental organizations in Marivan.

- There is meaningful relation between structural dimension of social capital and organizational silence of employees in governmental organizations in Marivan.

\section{RESEARCH METHODOLOGY}

The method of the research was descriptive with from the correlation style and the statistics society of the research was consisted of all employees in governmental organizations of Marivan (600), that 377 persons was determined as statistics sample based upon the Cochran's formulation; the categorized sampling method was proportionally used. The information (data) collector tool for social capital and organizational silence was the ascertained questionnaire that was distributed after estimating its validity and stability. The social capital questionnaire was included of 19 questions that its stability was measured by the Cronbach's alpha. For data analysis, the methods of descriptive statistics analysis (consist of tables and diagrams, measures of central dispersion tendency, frequencies and ...) and methods of inferential statistics analysis (Correlation, Pearson and Regression coefficients) were used. In this research, the statistics tests was done by assistant of SPSS software. 


\section{RESULTS}

\section{A. Descriptive results of research}

\section{The condition of organizational silence behaviour of employees}

Overall, for evaluating and measuring the level of organizational silence of employees in governmental organizations in Marivan, the triple dimensions (Altruistic, Defensive and Submissive Silence) were used; regarding to the table (1), it can be said that the level of organizational silence of employees is lower than the average rates (Average $=42.8$ from the minimum rate of 15 and maximum 75).

Table (1): Descriptive statistics about the level of organizational silence of employees

\begin{tabular}{|c|c|c|c|c|c|c|}
\hline Variable & Number & $\begin{array}{c}\text { Variation } \\
\text { Range }\end{array}$ & $\begin{array}{c}\text { Minimum } \\
\text { Statistic }\end{array}$ & $\begin{array}{c}\text { Maximum } \\
\text { Statistic }\end{array}$ & Average & $\begin{array}{c}\text { Standard } \\
\text { Deviation }\end{array}$ \\
\hline $\begin{array}{c}\text { Organizational } \\
\text { Silence }\end{array}$ & 377 & 55 & 20 & 75 & $42 / 8$ & $11 / 4$ \\
\hline $\begin{array}{c}\text { Altruistic } \\
\text { Silence }\end{array}$ & 377 & 19 & 6 & 25 & 14 & $4 / 3$ \\
\hline $\begin{array}{c}\text { Defensive } \\
\text { Silence }\end{array}$ & 377 & 19 & 6 & 25 & $13 / 7$ & $4 / 1$ \\
\hline $\begin{array}{c}\text { Submissive } \\
\text { Silence }\end{array}$ & 377 & 20 & 5 & 25 & $14 / 9$ & $4 / 2$ \\
\hline
\end{tabular}

\section{The condition of social capital of employees}

For evaluating and measuring the level of social capital of employees, the triple dimensions (structural, cognitive and relational dimensions) were used. Regarding to the table (2), it can be said that the level of social capital of employees is almost higher than the average rates (Average $=61.4$ from the minimum rate of 19 and maximum 95).

Table (2): Descriptive statistics about the level of social capital of employees

\begin{tabular}{|c|c|c|c|c|c|c|}
\hline Variable & Number & $\begin{array}{c}\text { Variation } \\
\text { Range }\end{array}$ & $\begin{array}{c}\text { Minimum } \\
\text { Statistic }\end{array}$ & $\begin{array}{c}\text { Maximum } \\
\text { Statistic }\end{array}$ & Average & $\begin{array}{c}\text { Standard } \\
\text { Deviation }\end{array}$ \\
\hline $\begin{array}{c}\text { Organizational } \\
\text { Silence }\end{array}$ & 377 & 55 & 38 & 93 & $61 / 4$ & $10 / 8$ \\
\hline $\begin{array}{c}\text { Altruistic } \\
\text { Silence }\end{array}$ & 377 & 21 & 9 & 30 & $19 / 7$ & $4 / 4$ \\
\hline $\begin{array}{c}\text { Defensive } \\
\text { Silence }\end{array}$ & 377 & 22 & 11 & 33 & $20 / 2$ & $4 / 8$ \\
\hline $\begin{array}{c}\text { Submissive } \\
\text { Silence }\end{array}$ & 377 & 16 & 14 & 30 & $21 / 5$ & $3 / 1$ \\
\hline
\end{tabular}

\section{B. the testing of hypothesises}

The achieved results of $\mathrm{R}$ test of Regression show that the social capital and organizational variables of employees have relation together at rate of $(-0 / 731)$ that the intensity of relation was powerful and the correlation kind was negative (reverse) and also the measured significance level $(\operatorname{sig}=0 / 000)$ is lower than the research alpha $(\alpha=0 / 05)$ that shows the significant relation between the two mentioned variables, therefore the main hypothesis is temporarily confirmed, so according to the results, it can be said that as the social capital of employees increases, their organizational silence will decrease (going forward in reverse direction). 
Table (3): The correlation testing of relation between social capital and its dimensions and the level of organizational silence of employees

\begin{tabular}{|l|l|l|l|l|}
\hline \multirow{2}{*}{$\begin{array}{c}\text { Independent } \\
\text { Variable }\end{array}$} & \multicolumn{3}{|l|}{ Dependent Variable } & \multicolumn{2}{|l|}{$\begin{array}{l}\text { Organizational } \\
\text { Behaviour }\end{array}$} \\
\cline { 2 - 5 } & $\begin{array}{l}\text { Social Capital } \\
\text { Dimensions }\end{array}$ & $\begin{array}{l}\text { Correlation } \\
\text { Intensity }\end{array}$ & $\begin{array}{l}\text { Significance } \\
\text { Level }\end{array}$ & $\begin{array}{l}\text { Confirmed/Not } \\
\text { Confirmed }\end{array}$ \\
\hline Hypothesis 1 & $\begin{array}{l}\text { Relational } \\
\text { Dimension }\end{array}$ & $-0 / 583$ & $0 / 000$ & Confirmed \\
\hline Hypothesis 2 & $\begin{array}{l}\text { Cognitive } \\
\text { Dimension }\end{array}$ & $-0 / 587$ & $0 / 000$ & Confirmed \\
\hline Hypothesis 3 & $\begin{array}{l}\text { Structural } \\
\text { Dimension }\end{array}$ & $-0 / 747$ & $0 / 000$ & Confirmed \\
\hline Main Hypothesis & Social Capital & $-0 / 731$ & $0 / 000$ & Confirmed \\
\hline
\end{tabular}

The practise model of determinative factors of organizational silence behaviour by using the stepwise regression

The results of stepwise regression analysis of determinative factors in organizational silence show that social capital dimensions (structural, relational) are purely explaining $0 / 58$ percent for variance level of organizational silence in the studied organizations.

Table (4): The statistics of regression analysis of multi-variables in organizational citizenship behaviour

\begin{tabular}{|c|c|c|}
\hline $\begin{array}{c}\text { Multiple Correlation } \\
\text { Coefficient }\end{array}$ & Explaining Coefficient & $\begin{array}{c}\text { Corrected Explaining } \\
\text { Coefficient }\end{array}$ \\
\hline $0 / 835$ & $0 / 697$ & $0 / 687$ \\
\hline
\end{tabular}

Table (5): The statistics related to the independent variables that have remained from the regression model

\begin{tabular}{|c|c|c|c|c|c|}
\hline Variable Name & B & Std. B & Beta & T & Sig T \\
\hline Intercept & $2 / 213$ & $1 / 953$ & - & $1 / 133$ & $0 / 258$ \\
\hline $\begin{array}{c}\text { Structural Dimension } \\
\text { of Social Capital }\end{array}$ & $-1 / 602$ & $0 / 114$ & $-0 / 630$ & $-14 / 010$ & $0 / 000$ \\
\hline $\begin{array}{c}\text { Relational Dimension } \\
\text { of Social Capital }\end{array}$ & $-0 / 439$ & $0 / 105$ & $-0 / 187$ & $-4 / 167$ & $0 / 000$ \\
\hline
\end{tabular}

As it's obvious from the top table, among the variables which were entered in the equation, the dependent variable is orderly affecting more by structural and relational dimensions. The dependent variable (organizational silence) is firstly affected reversely from the structural dimension variable of social capital of employees, this variable is singly explaining 63 percent of the organizational silence variance among the studied society. Secondly, the dependent variable (organizational silence) is affected reversely from the relational dimension variable of social capital of employees, this variable is singly explaining 19 percent of the organizational silence variance among the studied society.

\section{DISCUSSING ABOUT CONCLUSION:}

The parameter of social capital level of employees in the structural dimension is the first effective dimension in organizational silence of employees in the studied organizations. What that in the structural dimension of social capital has importance is the existence or lack of network connections between the employees and their network configuration in social relations. Social linkages and relations are considered in the theory of network analysis as social capital and person's 
property and the person can access to the resources and existed supports in the linkages by them. Hence, the qualification of social relations, the level and style of interactions and the kinds of supports which have be exchanged have so many importance. According to the high average of social capital of employees in structural dimension and also based on the various researches results, it can be concluded that the employees can have the possibility of profiting from the benefits such as accessing to the information, profiting from the co-workers guidance, advisement, emotional encouragement and support and financial assistance which this matter is achievable by social interactions of employees, and also makes the employees able to achieve more success in different fields of life and careers. Actually this linkages (connections) are the communications between the members of social relation network which are as a valuable resource that by making the mutual trust of employees to each other cause the realization of organization's goals and they improve and reinforce the stable norms of mutual relations and also facilitate the cooperation and communication, and reinforce the available information about people's reliability, so with the high level of social capital in this dimension, it can be expected that organizational silence of employees also have high level. The high level of social capital in this dimension keeps the relations of employees together and based on these relation, they reach to a possibility for supporting their colleagues. The parameter of social capital level of employees in the relational dimension is the second effective dimension in organizational silence of employees in the studied governmental organizations. The relational dimension of social capital of employees is referring to the level of mutual trust and relation between a social unit's members. The main notifying focus of the relational dimension of social capital is stable based on the special relations such as: respect, trust, bailment, kindness and intimacy that people show in their interactions with others; based on the achieved results, the social capital average in this dimension is also equal with the average of amounts (marks) like other dimensions. Regarding to the high level of social capital in this dimension, it can be expected that the trust increases among the employees. According to mutual trust among the employees, useful behaviours such as intimacy and compassion are increased that in this case it can be in the line with the increment of organizational silence components. Totally it should be said that the social capital from an attitude is management phenomenon and define various features for which is consisting of trust (norms), mutual values and behaviour, communications, cooperation, mutual commitment, mutual and networks cognition (Vilanova and Josa, 30: 2003). The organizations that have higher levels of social capital are probably more successful than their competitions with lower level of social capital. Social capital also has a powerful effects of different aspects and dimensions of person's life. Some of these effects are as follows: have longer life, more educational success, the income equality levels, more welfare for children and less misusing from them, less official corruption and better performance of governmental systems (units) and also better economic performance through more trust and costs reduction in trading with others (Share'pour, 2006).

\section{References}

[1] Alvani, Mehdi. Shirvani, Alireza (2003). Social capital, the guiding principle of development. Tadbir Monthly, number 47.

[2] Alvani, Mehdi et al (2007). Role of social capital in management developing of organizational knowledge. Journal of management sciences. 2(5): 35 - 70.

[3] Alvani, Syed Mehdi and Abdullapour, Mona (2008). Role of social capital in organizational entrepreneurship. Journal of management sciences. 27: 5 - 26.

[4] Portes, Alhander (2005). Social capital: its sources and usages in modern sociology. Translation by Afshin Khakbaz and Hasan Pouyan. Social capital, trust and democracy and development. Tehran: Shirazeh publication. 
[5] Danaiefard, Hasan and Panahi, Belal (2010). The analysis of job outlook of employees in governmental organizations. Explaining the atmosphere of organizational silence and organizational silence behaviour. The bulletin of management development. 2(3): 1 - 19.

[6] Share'pour, Mahmud (2006). Social capital - conceptualization, assessment and reasons of policy-making. The management and planning organization of Mazandaran.

[7] Sydanlo, Marzieh (2002). Role of organizational citizenship behaviour on employees silence in governmental section. M.A. thesis, college (faculty) of management and accounting.

[8] Archibong, Chi, Anyansi (2004). Technology, Infrastructure and Entrepreneurship: Role of the Government in Building a sustainable Economy, School of Business and Economics North Carolian A \& T State University.

[9] Avery, D. R. and Quinones, M. A. (2002). Disentangling the effects of voice: the incremental roles of opportunity, behavior, and instrumentality in predicting procedural fairness. Journal of Applied Psychology, 87, 81-6.

[10]Bolino Mark and Turnley William (2003), Going the extra mile: cultivating and managing employee citizenship behavior, Academy of Management Executive, 17(3):60 - 71

[11]Leana, C. R. and Van Buren, H. J. (1999). Organizational social capital and employment practices, Academy of Management Review. 24: 538- 54.

[12]Lock Lee, L. (2005) .Knowledge Management Tool and Techniques, Elsevier Butterworth Heinemann, (45): 123-130.

[13] Morrison, E. W. and Milliken, F. J. (2000). Organizational silence: a barrier to change and development in a pluralistic world. Academy of Management Review, 25, 706-25.

[14]Nahapiet, J. and Ghoshal, S. (1998). Social capital, intellectual capital, and the organizational advantage, Academy of Management Review. 23(2): 242 -266.

[15]Pinder, C. C. and Harlos K. P. (2001). Employee silence: quiescence and acquiescence as responses to perceived injustice'. In Rowland, K. M. and Ferris, G. R. (Eds), Research in Personnel and Human Resources Management, 20, 331-69.

[16] Vilanava \& Josa (2003).Social capital as a Managerial Phenomenon, Department of Industrial Engineering \& Management; Tampere University of Technology. 